\title{
Characteristics of Intraoperative Abnormal Hemodynamics During Resection of an Intra-fourth Ventricular Tumor Located on the Dorsal Medulla Oblongata
}

\author{
Makoto IDEGUCHI, ${ }^{1}$ Koji KAJIWARA,,${ }^{1}$ Koichi YoshIKAWA, ${ }^{1}$ Hirokazu SADAHIRO, ${ }^{1}$ \\ Sadahiro NOMURA, ${ }^{1}$ Masami FUJII, ${ }^{1}$ and Michiyasu SUZUKI ${ }^{1}$ \\ ${ }^{1}$ Department of Neurosurgery, Yamaguchi University Graduate School of Medicine, \\ Ube, Yamaguchi
}

\begin{abstract}
Abnormal hemodynamics during extirpation of a para-medulla oblongata (MO) tumor is common and may be associated with direct vagal stimulation of the medullary circuit. However, resection of tumors on the dorsal MO may also induce hemodynamic instability without direct vagal stimulus. The objective of this study was to examine the characteristics of hemodynamic instability unrelated to vagal stimulus during dissection of an intra-fourth ventricular tumor with attachment to the dorsal MO. A retrospective analysis was performed in 13 patients. Abnormal hemodynamics were defined as a $>20 \%$ change from the means of the intraoperative mean arterial pressure (MAP) and heart rate (HR). Relationships of intraoperative hemodynamics were evaluated with various parameters, including the volume of the MO. Six patients (46.2\%) had intraoperative hypertension during separation of the tumor bulk from the dorsal MO. The maximum MAP and HR in these patients were significantly greater than those in patients with normal hemodynamics $(116.0 \pm 18.0 \mathrm{mmHg}$ versus $85.6 \pm 6.5 \mathrm{mmHg} ; 124.3 \pm 22.8 \mathrm{bpm}$ versus $90.5 \pm 14.7 \mathrm{bpm})$. All six cases with abnormal hemodynamics showed hemodynamic fluctuation during separation of the tumor bulk from the dorsal MO. The preoperative volume of the MO in these patients was $1.11 \mathrm{cc}$ less than that in patients with normal hemodynamics, but the volume after tumor resection was similar in the two groups $(5.23 \mathrm{cc}$ and $5.12 \mathrm{cc}$ ). This suggests that the MO was compressed by the conglutinate tumor bulk, with resultant fluctuation of hemodynamics. Recognition of and preparation for this phenomenon are important for surgery on a tumor located on the dorsal MO.
\end{abstract}

Key words: neurogenic vasomotor center, nucleus of the solitary tract, paramedullary tumor, sympathetic overstimulation, volume change of medulla oblongata

\section{Introduction}

Sudden fluctuations in blood pressure (BP) and heart rate (HR) are commonly seen during manipulation of a para-medulla oblongata (MO) tumor. This phenomenon is not well understood, but could be due to excitatory or destructive stimulation of the MO inducing instability in the cardiovascular system, since the neurogenic vasomotor center is located in the MO. ${ }^{5,6)}$ Essential hypertension has been associated with chronic elevation of sympathetic tone due to continuous compression of the pressor center in the rostral ventrolateral MO (RVLM) by vessels,

Received November 20, 2012; Accepted February 28, 2013 a phenomenon known as neurogenic hypertension. ${ }^{1,11,13,25,32)}$ Several reports have also suggested a relationship between hypertension and posterior fossa tumors, ${ }^{4,16,21,37)}$ with hypertension caused by damage of the vasomotor center due to direct compression of the MO. In most cases, vascular translocation or tumor resection leading to decompression of the MO has resulted in improvement of hypertension and tachycardia. . $^{4,10,12,16,37)}$

The mechanism of abnormal hemodynamics may be related to direct or indirect excitatory or inhibitory stimulation of the dorsal MO during extirpation of an intra-fourth ventricle tumor. A direct effect on the RVLM may not occur due to the difference between the actual location and 
the surgical view. The goal of the current study was to examine the characteristics of instability in the cardiovascular system during resection of an intra-fourth ventricle tumor located on the dorsal surface of the MO.

\section{Materials and Methods}

This study was performed as a retrospective review of clinical records and anesthesia charts of patients in our hospital with an intra-fourth ventricle tumor with attachment to the dorsal region of the MO shown on magnetic resonance imaging (MRI) from 2003 to 2009. Tumor removal was performed with a midline suboccipital or lateral suboccipital approach with electrophysiological monitoring of the cranial nerves from VI to XII for functional preservation and somatosensory evoked potential and auditory brainstem response monitoring of the brain stem and VIII nerve function. Final diagnoses were made by a pathologist at Yamaguchi University Hospital using surgical specimens and based on World Health Organization (WHO) criteria.

Surgery was performed under total intravenous anesthesia, such as propofol combined with remifentanil. The intravenous concentration of propofol was not monitored because real-time feedback of intravenous anesthetics is technically difficult. Therefore, the anesthesiologist monitored the anesthetic depth with reference to data from a target controlled infusion system, which can maintain the intravenous concentration at a target level by automatically regulating the drug infusion velocity using a computer. The anesthesiologist also determined the anesthetic depth from parameters such as BP, HR, body temperature, urinary volume, and blood gas analysis. The stability of the depth of anesthesia during microscopic surgery was maintained in all cases.

$\mathrm{BP}$ was monitored using an intraarterial catheter or automated cuff inflation device at the discretion of the anesthesiologist during the operation. Mean arterial pressure (MAP) was estimated using measured systolic and diastolic BPs by subtracting the diastolic pressure from the systolic pressure, multiplying by one-third, and then adding the diastolic pressure. Since 2009, MAP was automatically calculated by a computer in the anesthesia system. The mean intraoperative MAP (mMAP) and mean HR (mHR) were calculated using averages of stable BP and HR over a 10-min period from the start of microsurgery without a period of fluctuating BP or HR. Abnormal hemodynamics (abnormal hypertension or hypotension and tachycardia or bradycardia) were defined as a $>20 \%$ change from mMAP and mHR. Based on this criterion, the patients were divided into those with abnormal and normal hemodynamics for analysis.

MRI was performed with a Toshiba Visart 1.5T MRI scanner beginning in January 2003. Slice thickness was calculated from the distance between scans using contiguous $6.0-\mathrm{mm}$ slices from the skull base to the vertex, which is parallel to the orbitomeatal line. Tumor volume was calculated by multiplying the maximum dimension of each of three orthogonal views and dividing by two for the lesion with enhancement on gadolinium-enhanced T1-weighted MRI (Gd-MRI). The resection rate was calculated by subtracting the postoperative tumor volume from the preoperative tumor volume, dividing by the preoperative tumor volume, and then multiplying by 100 .

The volume of the $\mathrm{MO}$ was measured using the established protocol from a previous volumetric study. ${ }^{22,23)}$ The border between the pons and the MO was defined by a plane parallel to the upper rim of the pons-lower edge of the inferior colliculus plane, touching the lower rim of the pons. For the inferior border, a plane parallel to the mammillary body-posterior commissure plane was aligned as the posterior edge of the foramen magnum. These lines were manually outlined on each Gd-MRI slice. MR images of the MO determined as above were reconstructed at each slice thickness and transferred to a workstation (AZE Virtual Place FujinRaijin, AZE, Marunouchi Chiyoda-ku, Tokyo) for calculation of the MO volume using the voxel count method. ${ }^{22-24,26,27,34)}$ In this method, the input profile of a slice is displayed by window processing and sequencing of points. The number of voxels in the region is then calculated. The volume of the MO was obtained by multiplying the number of voxels by the precalculated volume of a voxel. Volumetric quantification of the MO was performed by two examiners blinded to the clinical data using MRI taken at admission and 3 months after the operation.

Statistical analyses were performed by Fisher exact test (for nonordered variables), Mann-Whitney $U$ test, paired t-test, and two sample t-test (for ordered variables). A value of $\mathrm{p}<0.05$ was considered significant in all analyses. Multivariate analysis was not performed due to the small number of patients in the study.

\section{Results}

The 13 patients in the study had a mean age ( \pm SD) (SD: standard deviation) of $16.6 \pm 15.4$ years and $6(46 \%)$ were male. All patients were shown to have an intra-fourth ventricular tumor with attachment to the dorsal region of the MO on Gd-MRI. Six patients (46.2\%) showed elevation of 
MAP or HR of $>20 \%$ from mMAP or mHR during surgery and were classified as having abnormal hemodynamics. The other seven patients had normal hemodynamics during the procedure. None of the 13 cases had abnormal hypotension or bradycardia in our series. The abnormal hemodynamics were controllable by regulating the depth of anesthesia and administration of antihypertensive drugs such as Ca blockers and $\beta$-blockers. The duration of the abnormal increase in MAP or HR was $44.8 \pm 25.3$ min (29-95 min), after which the parameter stabilized within the normal range.

There were no significant differences between patients with abnormal and normal hemodynamics in age $(10.5 \pm 5.6$ years old versus $21.9 \pm 19.4$ years old), male gender (4/6 [66.7\%] versus $2 / 7$ [28.6\%]),

Table 1 Demographic and clinical characteristics of patients

\begin{tabular}{|c|c|c|c|}
\hline Characteristic & A & B & $\begin{array}{l}\mathrm{p} \text { value } \\
\text { (univariate } \\
\text { analysis) }\end{array}$ \\
\hline \multicolumn{4}{|l|}{ Age (year) } \\
\hline Range & $6-21$ & $4-61$ & NS \\
\hline Average/Median & $10.5 / 8.5$ & $21.5 / 19.4$ & \\
\hline Men:Women, n & $4: 2$ & $2: 5$ & NS \\
\hline \multicolumn{4}{|l|}{ WHO classification (\%) } \\
\hline Grade I & $3(50 \%)$ & $4(57.1)$ & NS \\
\hline Grades II-IV & $3(50 \%)$ & $3(42.9)$ & \\
\hline \multicolumn{4}{|l|}{$\begin{array}{l}\text { Preoperative tumor } \\
\text { volume (cc) }\end{array}$} \\
\hline Range & $2.51-48.3$ & $7.9-89.2$ & NS \\
\hline Average & 29.0 & 38.7 & \\
\hline \multicolumn{4}{|l|}{ Tumor removal rate } \\
\hline$>95 \%$ & $6(100 \%)$ & $4(57.1 \%)$ & NS \\
\hline$<95 \%$ & $0(0.0 \%)$ & $3(42.9 \%)$ & \\
\hline \multicolumn{4}{|l|}{$\begin{array}{l}\text { Preoperative volume of } \\
\text { medulla (cc) }\end{array}$} \\
\hline Range & $3.08-4.42$ & $4.3-5.3$ & 0.019 \\
\hline Average & 3.75 & 4.87 & \\
\hline \multicolumn{4}{|l|}{$\begin{array}{l}\text { Postoperative volume } \\
\text { of medulla (cc) }\end{array}$} \\
\hline Range & $4.21-6.56$ & $4.36-5.85$ & NS \\
\hline Average & 5.23 & 5.12 & \\
\hline $\begin{array}{l}\text { Intraoperative mMAP } \\
\text { (mmHg) }\end{array}$ & 115.8 & 124.3 & NS \\
\hline $\begin{array}{l}\text { Intraoperative mHR } \\
\text { (bpm) }\end{array}$ & 85.6 & 90.5 & NS \\
\hline
\end{tabular}

A: group in which the rate of change from mMAP or mHR is $20 \%$ or more, $\mathrm{B}$ : group in which the rate of change from mMAP or mHR is $20 \%$ or less, NS: not significant, WHO: World Health Organization, mMAP: mean of mean arterial pressure, mHR: mean of heart rate. and WHO classification Grade I (3/6 [50\%] versus $4 / 7[57.1 \%])$ and Grades II-IV (3/6 [50\%] versus 3/7 $[42.9 \%]$ ), or in preoperative tumor volume, tumor resection rate, or pathological diagnosis (Tables 1 and 2). In patients with abnormal hemodynamics, the mean duration from the start of microsurgery until an episode of hemodynamic fluctuation was $121.6 \pm 35.7 \mathrm{~min}$, consistent with the period of extirpation of the tumor bulk from the dorsal MO (Table 2).

The intraoperative mMAP and mHR in all cases were $80.0 \pm 8.43 \mathrm{mmHg}$ and $78.8 \pm 13.2 \mathrm{bpm}$, respectively. No patients had a history of cardiovascular disease, hypertension, or stroke; and no intraoperative arrhythmia, myocardial ischemia, or abnormal hypotension or bradycardia was seen on electrocardiograms under monitoring by an anesthesiologist. There was no significant difference in intraoperative mMAP and mHR between the two groups (Table 1 and Fig. 1A). However, the maximal MAP and HR were significantly higher in patients with abnormal hemodynamics $(116.0 \pm 18.0 \mathrm{mmHg}$ versus $85.6 \pm 6.5 \mathrm{mmHg}, \mathrm{p}<0.005 ; 124.3 \pm 22.8 \mathrm{bpm}$ versus $90.5 \pm 14.7 \mathrm{bpm}, \mathrm{p}<0.01$ ) (Fig. 1B). The maximal MAP and HR in these patients were also significantly higher than mMAP and mHR ( $p<0.05$ and $p<0.01$ ) (Fig. 2A). In contrast, there was no significant difference between maximal MAP and mMAP or between maximal HR and mHR in patients with normal hemodynamics (Fig. 2B).

The preoperative volume of the MO in patients with abnormal hemodynamics was significantly smaller than that in those with normal hemodynamics (Table $1 ; p=0.019$ ). In patients with abnormal hemodynamics, the postoperative volume of the MO was significantly larger than the preoperative volume $(5.23 \pm 0.88 \mathrm{cc}$ versus $3.75 \pm 0.55 \mathrm{cc}, \mathrm{p}=$ 0.026) (Fig. 3A), whereas there was no significant pre- to postoperative volume change in patients with normal hemodynamics $(4.87 \pm 0.41 \mathrm{cc}$ versus 5.12 $\pm 0.61 \mathrm{cc}, \mathrm{p}=0.16$ ) (Fig. 3B). The percentage preto postoperative volume change was significantly greater in patients with abnormal hemodynamics compared to those with normal hemodynamics (40.1 $\pm 19.0 \%$ versus $5.28 \pm 10.0 \%, p<0.002$ ) (Fig. $3 \mathrm{C}$ ).

Illustrative case (Case 2 in Table 2): A 10-yearold girl had suffered from aggravated nausea and vomiting for 2 months and was referred to our hospital. Her nausea and appetite loss persisted after admission, but no neurological deficit was apparent, including in cerebellar function. All vital signs were unremarkable. Gadolinium-enhanced MRI showed a heterogeneously enhanced, poorly circumscribed mass lesion with partial cyst formation located 
Table 2 Intraoperative cardiovascular hemodynamics

\begin{tabular}{|c|c|c|c|c|c|c|c|c|c|c|}
\hline Case & $\begin{array}{l}\text { Sex/ } \\
\text { age }\end{array}$ & $\begin{array}{c}\text { Pathological } \\
\text { diagnosis }\end{array}$ & $\begin{array}{l}\text { Volume of } \\
\text { tumor (cc) }\end{array}$ & $\begin{array}{l}\text { Removal } \\
\text { rate }\end{array}$ & $\begin{array}{l}\text { Mean of } \\
\text { MAP }\end{array}$ & $\begin{array}{c}\text { Mean of } \\
\text { HR }\end{array}$ & $\begin{array}{l}\text { Maximal } \\
\text { MAP/HR }\end{array}$ & $\begin{array}{c}\Delta(\% \Delta) \\
\text { MAP }\end{array}$ & $\begin{array}{c}\Delta /(\% \Delta) \\
\text { HR }\end{array}$ & $\begin{array}{l}\text { Duration of } \\
\text { procedure } \\
\text { (min) }\end{array}$ \\
\hline$\underline{1}$ & $\mathrm{M} / 7$ & CPP & 2.5 & $>95 \%$ & $\underline{62.7 \pm 2.5}$ & $55.0 \pm 1.1$ & $\underline{92.3 / 88}$ & $29.6(46.7)$ & $33.2(60.0)$ & $\underline{55}$ \\
\hline$\underline{2}$ & $\mathrm{~F} / 10$ & $\underline{\mathrm{AE}}$ & $\underline{17.4}$ & $\geq 95 \%$ & $\underline{89.8 \pm 4.5}$ & $\underline{63.6 \pm 1.1}$ & $\underline{125 / 149}$ & $\underline{35.2(39.2)}$ & $\underline{68.4(84.9)}$ & $\underline{125}$ \\
\hline 3 & $\mathrm{~F} / 20$ & $\overline{\mathrm{Ep}}$ & 17.1 & $>95 \%$ & $73.5 \pm 2.4$ & $65.4 \pm 1.6$ & $81 / 70$ & $7.7(10.5)$ & $5.8(9.03)$ & - \\
\hline$\underline{4}$ & $\mathrm{M} / 21$ & $\underline{\mathrm{He}}$ & $\underline{46.4}$ & $>95 \%$ & $\underline{86.0 \pm 2.6}$ & $\underline{81.0 \pm 3.9}$ & $131 / 133$ & $43.7(50.0)$ & $\underline{51.4(63.0)}$ & $\underline{140}$ \\
\hline 5 & $\mathrm{M} / 27$ & Ep & 40.7 & $>95 \%$ & $80.3 \pm 3.8$ & $88.5 \pm 2.2$ & $88.2 / 95$ & $2.40(2.80)$ & $13.2(16.1)$ & - \\
\hline$\underline{6}$ & $\mathrm{M} / 12$ & CPP & $\underline{31.5}$ & $>95 \%$ & $\underline{75.1 \pm 2.0}$ & $\underline{88.7 \pm 3.0}$ & $97.4 / 113$ & $21.3(28.0)$ & $26.8(31.1)$ & $\underline{135}$ \\
\hline$\underline{7}$ & $\underline{\mathrm{F} / 6}$ & $\underline{\mathrm{Ep}}$ & $\underline{48.3}$ & $\geq 95 \%$ & $\underline{88 \pm 2.8}$ & $\underline{83.0 \pm 2.9}$ & $\underline{114 / 118}$ & $28.7(33.6)$ & $\underline{38.4(48.2)}$ & $\underline{145}$ \\
\hline 8 & $\mathrm{~F} / 24$ & Ep & 27.2 & $<95 \%$ & $83.7 \pm 2.9$ & $86.6 \pm 4.4$ & $91.3 / 90.5$ & $7.76(9.29)$ & $3.98(4.60)$ & - \\
\hline 9 & $\mathrm{~F} / 61$ & $\mathrm{He}$ & 25.1 & $<95 \%$ & $85.7 \pm 3.7$ & $61.6 \pm 2.9$ & $90.9 / 72$ & $10.2(12.6)$ & $10.8(17.6)$ & - \\
\hline 10 & $\mathrm{~F} / 11$ & $\mathrm{He}$ & 63.7 & $<95 \%$ & $88.3 \pm 2.4$ & $86.9 \pm 2.2$ & $92 / 95$ & $4.6(5.26)$ & $12.6(15.3)$ & - \\
\hline 11 & $\mathrm{M} / 7$ & $\underline{\mathrm{AE}}$ & 27.9 & $>95 \%$ & $92.0 \pm 2.7$ & $\underline{86.3 \pm 1.9}$ & $153 / 160$ & $\underline{66.6(77.1)}$ & $84.2(111.1)$ & $\underline{135}$ \\
\hline 12 & $\mathrm{~F} / 6$ & $\mathrm{Ep}$ & 7.9 & $>95 \%$ & $71.7 \pm 1.1$ & $92 \pm 1.1$ & $76.9 / 101$ & $4.48(6.19)$ & $10.6(11.7)$ & - \\
\hline 13 & $\mathrm{M} / 4$ & AA & 89.2 & $>95 \%$ & $68.9 \pm 1.9$ & $103.9 \pm 2.4$ & 78.6/110 & $9.31(13.4)$ & $8.0(7.84)$ & - \\
\hline
\end{tabular}

AA: anaplastic astrocytoma, AE: anaplastic ependymoma, CPP: choroid plexus papilloma, $\Delta$ HR: delta between intraoperative maximal HR and mHR, $\triangle$ MAP: delta between intraoperative maximal MAP and mMAP, $\% \Delta H R$ : percent value of $\Delta H R$ for mHR, $\% \triangle \mathrm{MAP}$ : percent value of $\triangle \mathrm{MAP}$ for mMAP, Ep: ependymoma, He: hemangioblastoma. Duration of procedure: duration from start of microsurgery to episode of abnormal hemodynamics. Underlined entries indicate that abnormal cardiovascular hemodynamics occurred during the operation.
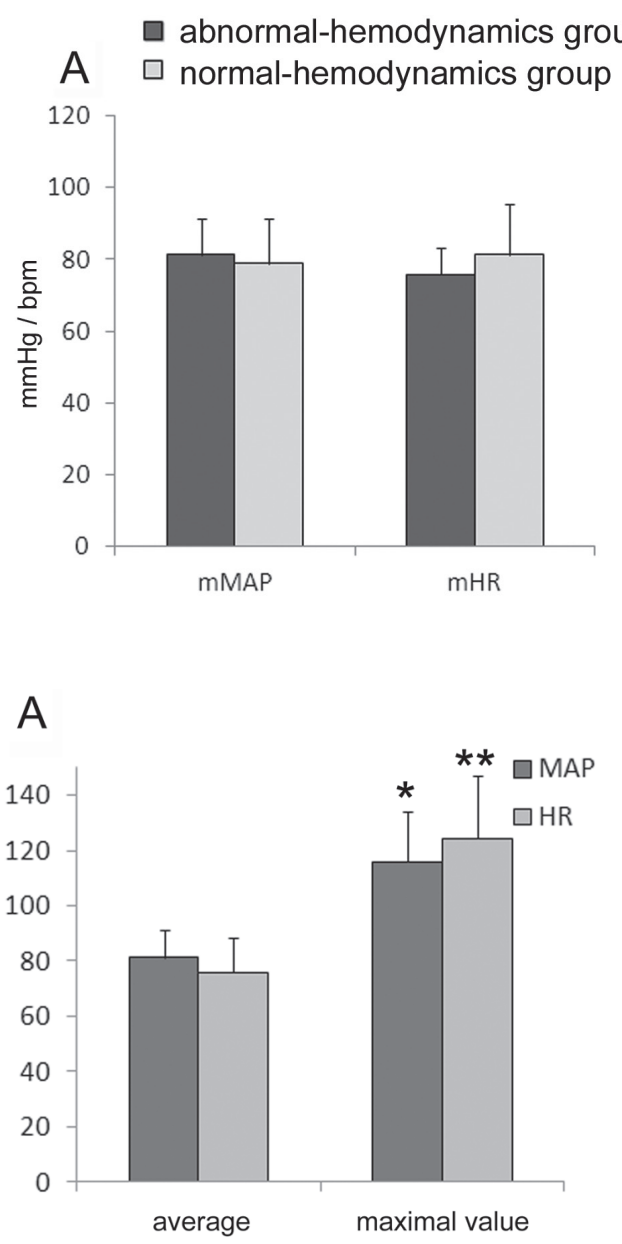

abnormal-hemodynamics group
B

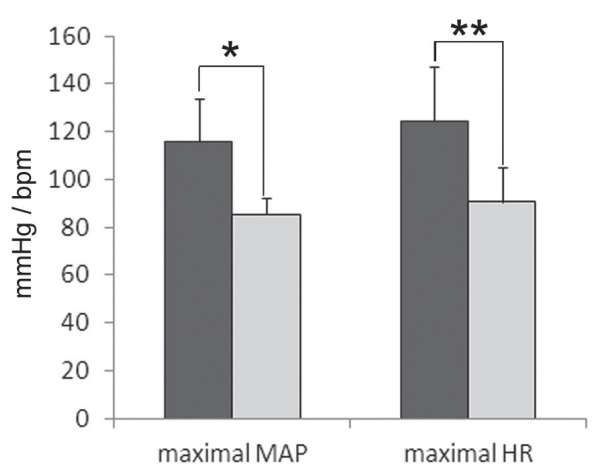

B

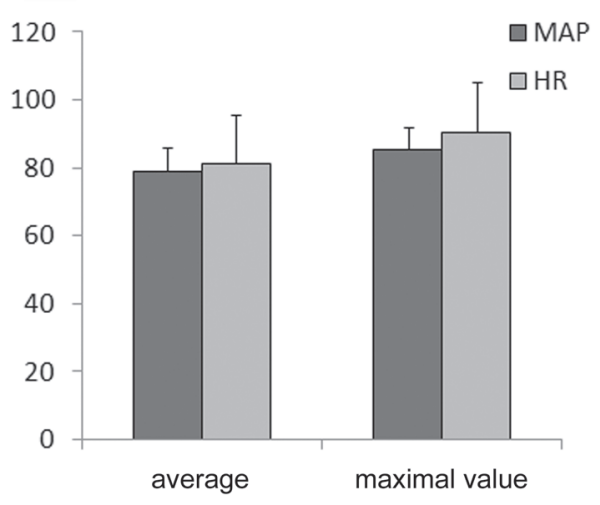

normal-hemodynamics group
Fig. 1 Comparison of intraoperative mMAP and $\mathrm{mHR}$ (A) and maximal MAP and HR (B) between patients with abnormal and normal hemodynamics. ${ }^{*} \mathbf{p}=\mathbf{0 . 0 0 2 ,}{ }^{*} \mathrm{p}=\mathbf{0 . 0 0 8}$. HR: heart rate, MAP: mean arterial pressure, mMAP: mean intraoperative MAP, mHR: mean HR. 
A

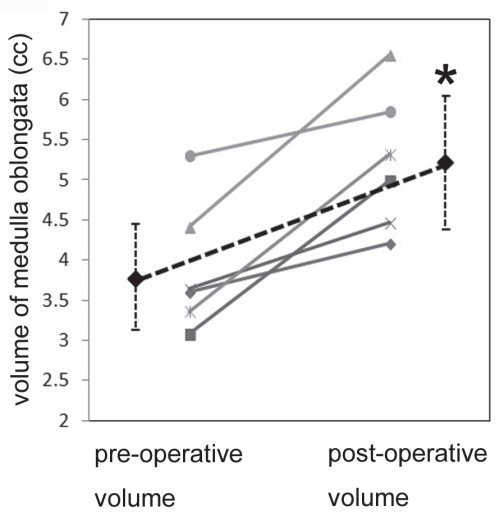

B

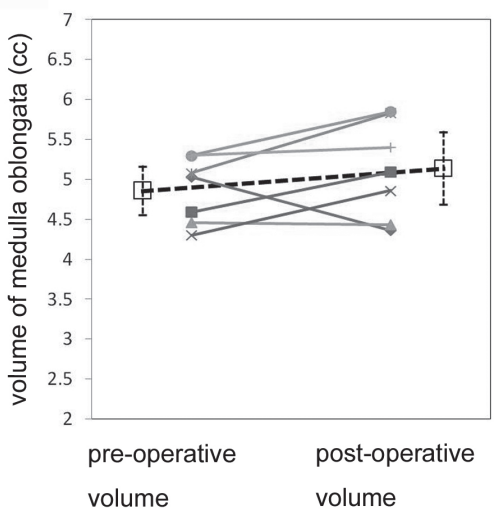

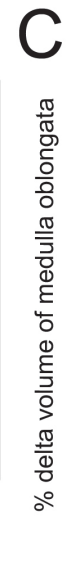

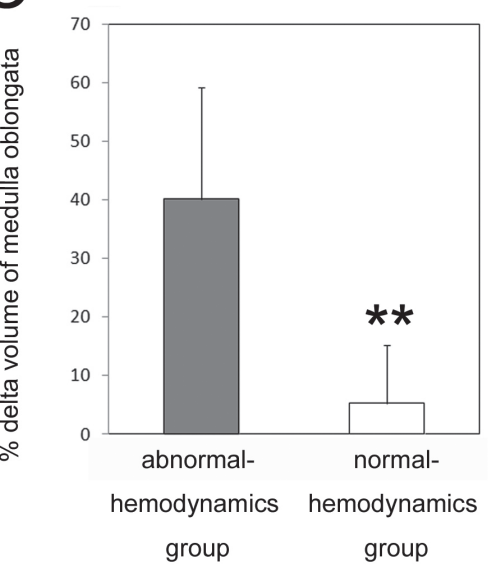

Fig. 3 A, B: Pre- to post-operative volume changes of the medulla oblongata in patients with abnormal (A) and normal (B) hemodynamics. The closed (A) and open (B) squares with error bars (standard deviation) show the average volumes. C: Percentage increase in the preoperative volume in each group. ${ }^{*} p=0.026,{ }^{* *} p=0.002$.
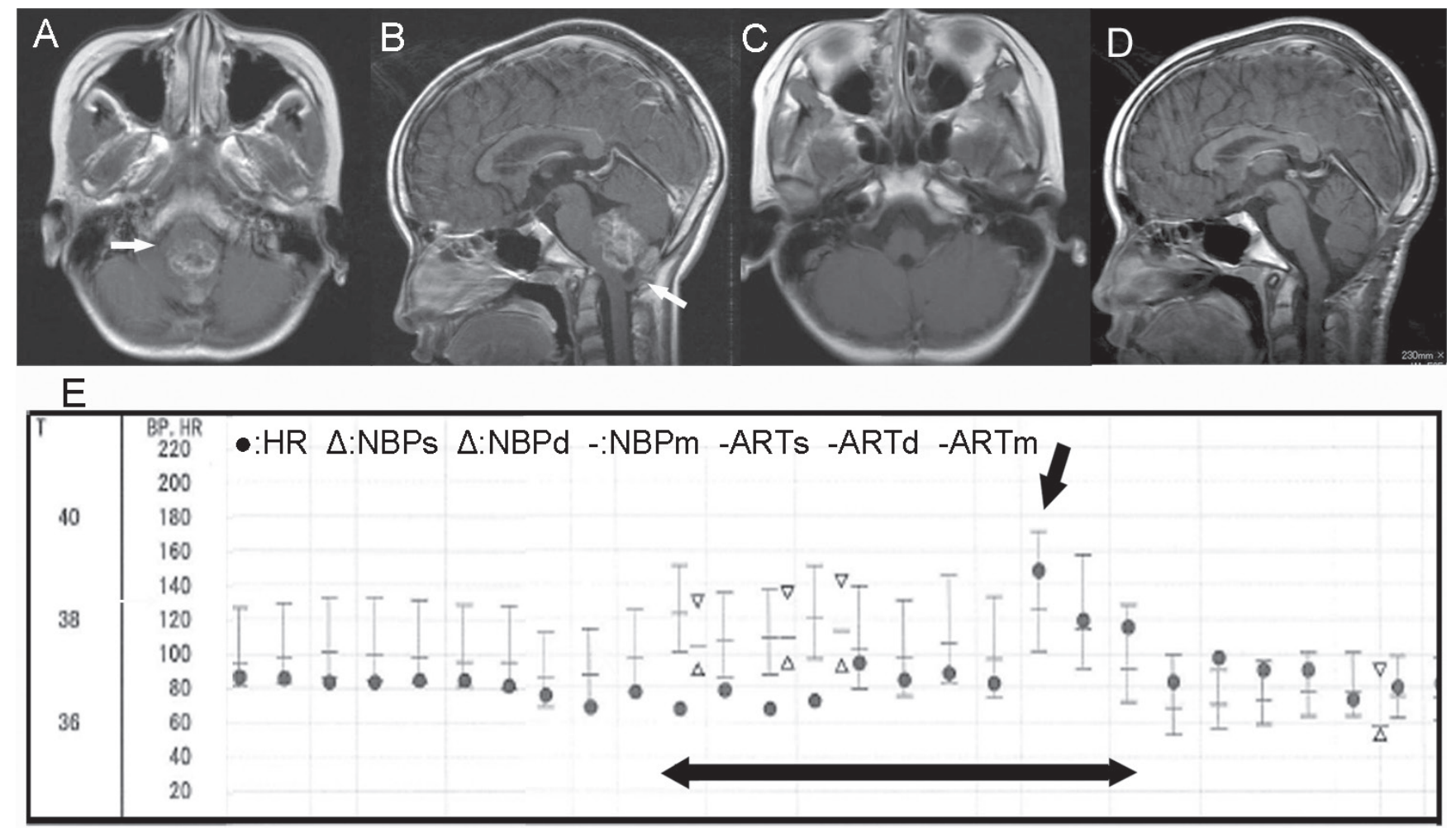

Fig. 4 A-E: Preoperative (A: axial view, B: sagittal view) and postoperative (C: axial view, D: sagittal view) gadolinium-enhanced magnetic resonance imaging (MRI) and (E) anesthesia chart in an illustrative case. E: Bilateral-facing black arrows indicate a period of fluctuating blood pressure (BP) and heart rate (HR), and the black arrow indicates the points of maximal MAP and HR. ARTd: diastolic arterial pressure, ARTm: mean of arterial pressure, ARTs: systolic arterial pressure, NBPd: noninvasive diastolic blood pressure, NBPm: mean of noninvasive blood pressure, NBPs: noninvasive systolic blood pressure. 
behind the brain stem (Fig. 4A, B). The results of laboratory tests, including for tumor markers, were within the normal range. The mean preoperative $\mathrm{BP}$ and $\mathrm{HR}$ were $104.8 \pm 3.8 / 74.9 \pm 8.7 \mathrm{mmHg}$ and $63.6 \pm 1.14 \mathrm{bpm}$, which were also within normal ranges. The preoperative volume of the tumor and MO were $17.4 \mathrm{cc}$ and $3.08 \mathrm{cc}$, respectively (Table 2 and Fig. 3A; line with squares; $\square$ ). The patient underwent bilateral suboccipital craniectomy for total removal of the tumor. It was difficult to detect the border between the tumor bulk and arachnoid plane and to separate the tumor from the parenchyma of the dorsal MO because of tight adhesion. During manipulation of the dorsal side of the MO, BP and HR suddenly increased to 170/102 mmHg (MAP = $125 \mathrm{mmHg}$ ) and $149 \mathrm{bpm}$, respectively, without any apparent reason (Fig. 4E). Thereafter, BP and HR were stabilized by the anesthesiologist, and the postoperative course has been stable to date. Postoperative MRI indicated total tumor resection (approximately 98\%) with transient mild right abducens nerve palsy and lower cranial nerve palsy neurologically (Fig. 4C, D). The postoperative volume of the MO was $4.99 \mathrm{cc}$, which represented an increase of 1.91 cc $(62.0 \%)$ compared to the preoperative volume (Fig. 3A; line with squares; $\mathbf{\square})$.

\section{Discussion}

In the present study, $46 \%$ of patients who underwent surgical resection of a brain tumor exhibited fluctuating cardiovascular hemodynamics when the dorsal side of the MO was manipulated to extirpate the tumor. The anesthesia chart and operation video showed that no factors affected the cardiovascular hemodynamics other than the actual microsurgical manipulation; that is, mechanical stimulation of the dorsal MO influenced the hemodynamics directly. The time of hemodynamic fluctuation was also consistent with the period of tumor manipulation. It is common knowledge among neurosurgeons that resection of a paramedullary tumor can affect the BP or HR, as discussed above. Jannetta and Gendell postulated that compression of the pressor center in the RVLM results in chronic overstimulation of the sympathetic nervous system, leading to systemic (essential) hypertension. ${ }^{18)}$ Direct compression of the RVLM by blood vessels and the tumor bulk can also induce hypertension. ${ }^{4,10,12,16,37)}$ However, all cases in our series underwent surgery for tumors located on the dorsal side of the MO and none required manipulation on the ventral to lateral side. Therefore, we suggest that direct manipulation of the dorsal MO can induce fluctuating cardiovascular hemodynamics.

The medullary circuit related to cardiovascular control involves the nucleus of the solitary tract (NTS), the nucleus ambiguous, and the rostral and caudal ventrolateral MO. ${ }^{14)}$ The NTS, which is located dorsal to the $\mathrm{MO}$, is the site of the first synapse of the viscerosensory afferents in the brain stem, including those related to cardiovascular baroreceptors and chemoreceptor afferents. From the NTS, baroreceptor afferent signals project to the caudal ventrolateral MO (CVLM). ${ }^{3,33,36)}$ The CVLM inhibits neurons in the RVLM that innervate preganglionic sympathetic neurons involved in controlling the heart and vascular beds. ${ }^{3,8,19,20,28,29)}$ In considering this neurogenic vasomotor center, we suggest that stimulus of the NTS by operative manipulation affects the cardiovascular control mechanism and then elicits the elevation of BP or HR. Suppressive stimulation or interruption of the afferent synapse to the NTS induces NTS inactivation, which induces inhibition of CVLM activation and then inhibition of RVLM suppression from the CVLM. Consequently, the RVLM could be activated chronically and could then induce intermediolateral nucleus activation, sympathetic overactivity, and finally systemic hypertension and tachycardia. ${ }^{17}$

Previous reports support this speculative mechanism, as follows. In animal models, hypertension can be produced by damage to the brain stem, especially the NTS bilaterally. ${ }^{9,30)}$ Disinhibition of the RVLM via deactivation of the CVLM by electrolytic lesions, injections of a GABAA receptor agonist, or blockade of GABAergic transmission in the RVLM also results in sustained sympathoexcitation and increases arterial pressure and HR., ${ }^{2,7,35)}$ Furthermore, blockade of the NTS with injections of a glutamatergic antagonist that induces deactivation of the CVLM also produces sympathoexcitation and increases the arterial pressure and HR. ${ }^{15)}$ We previously reported a rare case that exhibited continuous hypertension and tachycardia after fourth ventricular tumor resection; in this case we also suggested an etiology in which, directly or indirectly, NTS injury induced systemic sympathoexcitation based on the persistent high level of blood catecholamines after the operation. ${ }^{17)}$

We next considered the possibility that the volume of the MO was reduced due to compression by the tumor bulk, which could reflect the degree of adhesion between the dorsal MO and tumor tissue. This adhesion could also reflect the difficulty of surgical resection with minimal injury to the medullary parenchyma, which could influence the medullary circuit in the sympathetic mechanism. In fact, the preoperative volume of the MO in patients with 
abnormal hemodynamics was less than that in patients with normal hemodynamics. However, the volume recovered by $39.5 \%$ after tumor removal in patients with abnormal hemodynamics was $5.23 \pm 0.88 \mathrm{cc}$, which was similar to that in patients with normal hemodynamics $(5.12 \pm 0.61 \mathrm{cc})$. Thus, cases with a small preoperative volume could be prone to intraoperative cardiovascular fluctuation (Table 1 and Fig. 3A, B). The volume of the MO has previously been reported to be 5.0-6.0 cc, with larger volumes in men than in women and without an age difference. ${ }^{22)}$ Therefore, this volume is relatively constant among individuals, and age-related atrophy may not occur because the MO has regions associated with vital functions such as survival and breathing and is continuously used. ${ }^{22}$

In the current study, the mean preoperative volume of the MO in patients with abnormal hemodynamics was $3.75 \mathrm{cc}$, indicating compression by the tumor bulk. However, there was no significant relationship between the preoperative tumor volume and intraoperative cardiovascular fluctuation. BP and HR did show a tendency to fluctuate when complete tumor resection was achieved, but this relationship was not significant (Table 1). These findings suggest that the effect on BP or HR depends on the degree of adhesion of the tumor bulk and the medullary parenchyma or distribution of feeding arteries; that is, on the surgical difficulty, rather than the tumor bulk volume. We tried to evaluate surgical difficulty using categories such as the presence of the arachnoid plane, blood transfusion, and operation time, but it was difficult to determine a significant difference and omit personal bias (data not shown).

No case in our series showed sudden hypotension or bradycardia. However, an excitative stimulus administered to the NTS could induce an inhibitive stimulus in the cardiovascular system and result in these events or even possible cardiac arrest. Thus, preparation for temporary cardiac pacing during the operation should be made in advance.

There are some limitations to this study. The small number of patients is consistent with a case series and prevented calculations using multivariate linear regression models. In turn, this did not allow statistical verification of the independent effect of factors after adjustment for unknown confounders. A sample size of about 10-fold higher would be required to perform multivariate analysis. ${ }^{31)}$ Thus, establishment of the association and interaction between confounders and abnormal hemodynamics in tumor resection will require accumulation of further cases of intra-fourth ventricular tumors with dorsal MO attachment. However, the rarity of these cases makes this difficult, and thus our current results are of value as a basis to propose a plausible critical hypothesis.

Within these limitations, the results of the study suggest an important role for the nucleus of the solitary tract, which is involved in the medullary circuit related to neurogenic cardiovascular control, in intraoperative hypertension and tachycardia during extirpation of an intra-fourth ventricular tumor with dorsal MO attachment. It is vital for surgeons and anesthesiologists to recognize that sympathetic excitation or inhibition can be elicited via the neurogenic vasomotor center when planning surgery for this kind of tumor.

\section{Conflicts of Interest Disclosure}

The authors report no conflicts of interest concerning the work in this study.

\section{References}

1) Akimura T, Furutani Y, Jimi Y, Saito K, Kashiwagi S, Kato S, Ito H: Essential hypertension and neurovascular compression at the ventrolateral medulla oblongata: MR evaluation. AJNR Am J Neuroradiol 16: 401-405, 1995

2) Blessing WW: Depressor neurons in rabbit caudal medulla act via GABA receptors in rostral medulla. Am J Physiol 254: H686-H692, 1988

3) Brown DL, Guyenet PG: Electrophysiological study of cardiovascular neurons in the rostral ventrolateral medulla in rats. Circ Res 56: 359-369, 1985

4) Cameron SJ, Doig A: Cerebellar tumours presenting with clinical features of phaeochromocytoma. Lancet 1: 492-494, 1970

5) Ciriello J, Hochstenbach SL, Roder S: Central projections of baroreceptor and chemoreceptor afferent fibers in the rats, in Robin I, Barraco A (eds): Nucleus of the Solitary Tract. Boca Raton, Florida, CRC Press, 1993, pp 35-50

6) Dampney RA: Functional organization of central pathways regulating the cardiovascular system. Physiol Rev 74: 323-364, 1994

7) Dampney RA, Blessing WW, Tan E: Origin of tonic GABAergic inputs to vasopressor neurons in the subretrofacial nucleus of the rabbit. J Auton Nerv Syst 24: 227-239, 1988

8) Dampney RA, Goodchild AK, Tan E: Identification of cardiovascular cell groups in the brain stem. Clin Exp Hypertens A 6: 205-220, 1984

9) Doba N, Reis DJ: Acute fulminating neurogenic hypertension produced by brainstem lesions in the rat. Circ Res 32: 584-593, 1973

10) Frank H, Schobel HP, Heusser K, Geiger H, Fahlbusch R, Naraghi R: Long-term results after microvascular decompression in essential hypertension. Stroke 32: 2950-2955, 2001

11) Gajjar D, Egan B, Curè J, Rust P, VanTassel P, Patel 
SJ: Vascular compression of the rostral ventrolateral medulla in sympathetic mediated essential hypertension. Hypertension 36: 78-82, 2000

12) Geiger H, Naraghi R, Schobel HP, Frank H, Sterzel RB, Fahlbusch R: Decrease of blood pressure by ventrolateral medullary decompression in essential hypertension. Lancet 352: 446-449, 1998

13) Goldstein DS, Levinson PD, Zimlichman R, Pitterman A, Stull R, Keiser HR: Clonidine suppression testing in essential hypertension. Ann Intern Med 102: 42-49, 1985

14) Guyenet PG: Role of the ventral medulla oblongata in blood pressure regulation, in Loewy AD, Spyer KM (eds): Central Regulation of Autonomic Functions. New York, Oxford University Press, 1990, pp 145-167

15) Guyenet PG, Filtz TM, Donaldson SR: Role of excitatory amino acids in rat vagal and sympathetic baroreflexes. Brain Res 407: 272-284, 1987

16) Hedderwick SA, Bishop AE, Strong AJ, Ritter JM: Surgical cure of hypertension in a patient with brainstem capillary haemangioblastoma containing neuropeptide Y. Postgrad Med J 71: 371-372, 1995

17) Ideguchi M, Kajiwara K, Yoshikawa K, Kato S, Ishihara H, Fujii M, Fujisawa H, Suzuki M: Continuous hypertension and tachycardia after resection of a hemangioblastoma behind the dorsal medulla oblongata: relationship to sympathetic overactivity at the neurogenic vasomotor center. J Neurosurg 113: 369-373, 2010

18) Jannetta PJ, Gendell HM: Clinical observations on etiology of essential hypertension. Surg Forum 30: 431-432, 1979

19) Jeske I, Morrison SF, Cravo SL, Reis DJ: Identification of baroreceptor reflex interneurons in the caudal ventrolateral medulla. Am J Physiol 264: R169-R178, 1993

20) Jeske I, Reis DJ, Milner TA: Neurons in the barosensory area of the caudal ventrolateral medulla project monosynaptically on to sympathoexcitatory bulbospinal neurons in the rostral ventrolateral medulla. Neuroscience 65: 343-353, 1995

21) Langford HG, Sanford R, Smith R: Neurogenic hypertension in man: Reis, Barman-Gebber, or Carey syndrome. J Hypertens 5: S467-S469, 1987

22) Lee NJ, Park IS, Koh I, Jung TW, Rhyu IJ: No volume difference of medulla oblongata between young and old Korean people. Brain Res 1276: 77-82, 2009

23) Luft AR, Skalej M, Schulz JB, Welte D, Kolb R, Bürk K, Klockgether T, Voight K: Patterns of age-related shrinkage in cerebellum and brainstem observed in vivo using three-dimensional MRI volumetry. Cereb Cortex 9: 712-721, 1999

24) Luft AR, Skalej M, Welte D, Kolb R, Klose U: Reliability and exactness of MRI-based volumetry: a phantom study. J Magn Reson Imaging 6: 700-704, 1996

25) Makino Y, Kawano Y, Okuda N, Horio T, Iwashima Y, Yamada N, Takamiya M, Takishita S: Autonomic function in hypertensive patients with neurovascular compression of the ventrolateral medulla oblongata. J Hypertens 17: 1257-1263, 1999

26) Mancini M, Mainenti PP, Speranza A, Liuzzi R, Soscia E, Sabbatini M, Ferrara LA, Federico S, Salvatore M: Accuracy of sonographic volume measurements of kidney transplant. J Clin Ultrasound 34: 184-189, 2006

27) Mitchell JR, Karlik SJ, Lee DH, Fenster A: Computerassisted identification and quantification of multiple sclerosis lesions in MR imaging volumes in the brain. J Magn Reson Imaging 4: 197-208, 1994

28) Morrison SF, Callaway J, Milner TA, Reis DJ: Rostral ventrolateral medulla: a source of the glutamatergic innervation of the sympathetic intermediolateral nucleus. Brain Res 562: 126-135, 1991

29) Morrison SF, Reis DJ: Reticulospinal vasomotor neurons in the RVL mediate the somatosympathetic reflex. Am J Physiol 256: R1084-R1097, 1989

30) Nathan MA, Reis DJ: Chronic labile hypertension produced by lesions of the nucleus tractus solitarii in the cat. Circ Res 40: 72-81, 1977

31) Peduzzi P, Concato J, Kemper E, Holford TR, Feinstein AR: A simulation study of the number of events per variable in logistic regression analysis. J Clin Epidemiol 49: 1373-1379, 1996

32) Schobel HP, Frank H, Naraghi R, Geiger H, Titz E, Heusser K: Hypertension in patients with neurovascular compression is associated with increased central sympathetic outflow. J Am Soc Nephrol 13: 35-41, 2002

33) Schreihofer AM, Guyenet PG: The baroreflex and beyond: control of sympathetic vasomotor tone by GABAergic neurons in the ventrolateral medulla. Clin Exp Pharmacol Physiol 29: 514-521, 2002

34) Shirao S, Yoneda H, Ishihara H, Harada K, Ueda K, Sano Y, Kudomi S, Hayashi Y, Shigeeda T, Nakano K, Nomura S, Fujii M, Kato S, Suzuki M: Fate of clots in patients with subarachnoid hemorrhage following different surgical treatment modality: a comparison between surgical clipping and GDC embolization. Neurosurgery 68: 966-973, 2011

35) Sun MK, Guyenet PG: GABA-mediated baroreceptor inhibition of reticulospinal neurons. Am J Physiol 249: R672-R680, 1985

36) Sved AF, Ito S, Madden CJ: Baroreflex dependent and independent roles of the caudal ventrolateral medulla in cardiovascular regulation. Brain Res Bull 51: 129-133, 2000

37) Yagil Y, Futterweit W, Krakoff LR, Rubin H, Weinrauch H: Cerebellar tumor causing hypertensive crisis and simulating pheochromocytoma and Cushing's syndrome. Mt Sinai J Med 56: 56-58, 1989

Address reprint requests to: Makoto Ideguchi, MD, Department of Neurosurgery, Yamaguchi University School of Medicine, 1-1-1 Minami-kogushi, Ube, Yamaguchi 755-8505, Japan.

e-mail: ideguchi@yamaguchi-u.ac.jp 